\title{
Türk Sigortacılık Sektöründe Faaliyet Gösteren Hayat Dışı Sigorta Şirketlerinin Etkinlik Analizi
}

\author{
Efficiency Analysis Of Non-Insurance Insurance Companies Operating In The \\ Turkish Insurance Sector
}

Ibrahim Erem SAHIN*

Havva AKKOYUNCU**

\begin{abstract}
$\ddot{O} Z$
Türkiye'de sigortacllık sektörü finansal sistemlerde önemli bir yere sahiptir. Tüm sektörlerde olduğu gibi sigortacllk sektöründe de etkinlik çok önemlidir. Çalışmanın amacı 2014-2017 yılları itibariyle 23 tane hayat dlşı sigorta şirketinin etkinliklerini ölçmektir. Çalışmada parametrik olmayan yöntemlerden biri olan veri zarflama analizine göre CCR modeli ve Malmquist toplam faktör verimlilik endeksi kullanılmıştır. Dört girdi ve bir çıktının ele alındığl analizde ölçeğe göre sabit getirili ve girdi odakl model oluşturulmuştur. Analizde girdi olarak nakit ve nakit benzerleri, esas faaliyetten borçlar, sigortacılı teknik karşıllkkları ve ödenmiş sermaye; çıtkt olarak esas faaliyetten alacaklar kullanılmıştır. Analize göre firmaların ortalama etkinlik skorlarının en yüksek olduğu yıl 2015 iken, en düşük olduğu yıl ise 2016 yll olmuştur. Malmquist toplam faktör verimliliği endeksi sonuçları açısından ise bir önceki yıla göre 2015 yllinda 12 firma, 2016 yllinda 8 firma ve 2017 yllinda ise 13 firma pozitif gelişme göstermişlerdir.
\end{abstract}

\section{ANAHTAR KELIMELER}

Sigortacılık Sektörü, Hayat Dışı Sigorta Şirketleri, Veri Zarflama Analizi, CCR Modeli, Malmquist Toplam Faktör Verimlilik Endeksi

\begin{abstract}
The insurance sector in Turkey has an important place in the financial systems. As in all sectors, efficiency is very important in the insurance sector. The aim of this study is to measure the activities of 23 non-life insurance companies as of 2014-2017. In the study, CCR model and Malmquist total factor productivity index were used according to data envelopment analysis which is one of the nonparametric methods. In the analysis, where four inputs and output were discussed, a fixed-income and input-oriented model was created according to the scale. In the analysis, cash and cash equivalents, payables due to main operations, technical reserves and provisions (net) and paid in capital are used as input; and receivables from is used as output. According to the analysis, while the average activity scores of the companies were highest in 2015, the lowest year has been 2016. In terms of Malmquist total factor productivity index, 12 copmpanies in 2015, 8 companies in 2016 and 13 companies in 2017 showed positive development compared to the previous year.
\end{abstract}

\section{KEYWORDS}

Insurance Sector, Non-Life Insurance Companies, Data Envelopment Analysis, CCR Model, Malmquist Total Factor Productivity Index

\begin{tabular}{|c|c|c|}
\hline & $\begin{array}{c}\text { Makale Geliş Tarihi / Submission Date } \\
01.10 .2019\end{array}$ & $\begin{array}{c}\text { Makale Kabul Tarihi / Date of Acceptance } \\
\text { 26.11.2019 }\end{array}$ \\
\hline Atıf & $\begin{array}{l}\text { Şahin, İ.E. ve Akkoyuncu, H. (2019). } \\
\text { Etkinlik Analizi. Selçu Üniversitesi So }\end{array}$ & $\begin{array}{l}\text { Inde Faaliyet Gösteren Hayat D1ş1 Sigorta Şirketlerinin } \\
\text { sekokulu Dergisi, } 22 \text { (2), 840-852. }\end{array}$ \\
\hline
\end{tabular}

\footnotetext{
* Dr. Öğ. Üyesi, Selçuk Üniversitesi İktisadi ve İdari Bilimler Fakültesi, ibrahimeremsahin@ gmail.com, ORCID: 0000-0002-0442-8499

** Selçuk Üniversitesi İktisadi ve İdari Bilimler Fakültesi Muhasebe ve Finansman Tezli Yüksek Lisans, akkoyuncuhavva@ hotmail.com, ORCID: 0000-0003-0651-6457
} 


\section{GİRIŞ}

İnsanlar yaşamları süresince karşı karşıya kaldıkları tesadüfi veya insan davranışlarından doğan riskler sebebiyle nasıl korunmaları gerektiğini öğrenmiş ve bu hususta bir takım yöntemler geliştirmişlerdir. Geçmişten günümüze kadar oluşturulan bu yöntemler kişisel olarak tasarrufta bulunma ya da bir araya gelerek bir fon oluşturma, vakıf kurma olarak karşımıza çıkmıştır. Bu açıklamalar ışığında modern finans literatüründe sigorta kavramı doğmuştur.

Sigortacılıkla ilgili literatürde birçok tanım yapılmasına karşılık tam bir tanım yapmak zordur. Ancak yine de en kapsamlı tanım olarak yasa koyucunun yaptığı tanımdır. 6102 sayılı Türk Ticaret Kanunun 1401. Maddesinin I.bendine göre "Sigorta sözleşmesi, sigortacının bir prim karşılığında, kişinin para ile ölçülebilir bir menfaatini zarara uğratan tehlikenin, rizikonun, meydana gelmesi hâlinde bunu tazmin etmeyi ya da bir veya birkaç kişinin hayat süreleri sebebiyle ya da hayatlarında gerçekleşen bazı olaylar dolayısıyla bir para ödemeyi veya diğer edimlerde bulunmayı yükümlendiği sözleşmedir." diye tanımlanmaktadır (Çamlıbel vd., 2018: 2). O halde sigortacılık, olası bir yangın, kaza, ölüm gibi doğal afetler sonucunda hasar oluşması durumunda bina, eşya, mal ve can kaybından dolayı zarar gören sigortalının, sigortacı tarafından zararının ödenmesini sağlayan bir sözleşmedir. Günümüzde doğal afet, sağlık, seyahat, nakliyat ve ulaşım, havacılık, yangın, evlilik, gibi alanlarda sigorta poliçesi düzenlenmektedir. Düzenlenen bu poliçeler hayat, hayat dış1 ve emeklilik gibi başlıklar altında ifade edilir. Ülkemizde hayat dışı sigorta, hayat sigortalarına oranla daha yaygındır. Son yıllarda bireysel emeklilik ile ilgili düzenlemeler yapılması, bu dalda daha hızlı bir gelişme dönemini başlatmıştır (Çekici ve İnel, 2013: 136). Bunların dışında sigorta şirketleri, topladıkları primleri, gelecekte ortaya çıkabilecek tazminat taleplerine karşılık teminat olarak tutmakta; bu karş11ıkların bir kısmını sermaye piyasasına yönlendirerek, tasarrufların yatırımcılarla buluşmasını sağlamaktadır (Altan, 2010: 188). $\mathrm{O}$ halde sigortacılık sektörü optimal yatırım firsatlarının değerlendirilmesinde uygun bir kaynak oluşturmaktadır.

Sigortanın temel amacı toplumsal güvenliği sağlamaktır. Ancak toplumsal güvenliği sağlamanın yanında rekabet söz konusu olduğu durumlarda etkinlik ve verimlilik analizlerinin yapılması ön plana çıkmaktadır. Sektörde yer alan şirketlerin rekabet arenasında rakiplerinden geriye düşmemek için ileriye yönelik olarak belli başli stratejiler geliştirmesi de son derece önemli bir husustur.

Etkinlik ve verimlilik ilk bakışta aynı anlama geldiği düşünülse de birbirinden farklı kavramlardır. Verimlilik; sistemin sahip olduğu çıktıların, bu çıktıyı elde etmek için kullandığı girdilere oranıdır. Etkinlik ise en az girdi ile en yüksek çıktıyı elde etme durumudur.

\section{LITERATÜR}

Etkinlik kavramı birçok çalışmanın araştırma konusu olmakla birlikte yine birçok kişi tarafından ele alınan bir kavramdır. Etkinlik, üretim kaynaklarını veya girdilerini ne derecede iyi kullanarak çıktı üretebileceğini gösteren kavramdır. Mevcut girdiyi kullanarak en fazla çıktıyı üretmek ya da daha az girdi ile mevcut çıktıyı elde etmek şeklinde yorumlanır (Budak, 2011: 96).

Kaynakların belirli bir zaman diliminde ve hedeflenen sonuçlara göre değerlendirilmesi durumu ise etkinlik ölçümü olarak adlandırılmaktadır. Etkinlik ölçümünün belirlenmesinin nedeni etkin sınıra ulaşıp ulaşmama durumunun ortaya konulmasından kaynaklanmaktadır. Çünkü etkinlik sınırı girdi-çıktı bileşiminde en iyi performansı temsil eden bir sınırdır ve karar verme birimleri de bu sınırları belirleyici bir etkendir. Sınırda olmayan karar verme birimleri \%100 etkinliğin altında bir etkinliğe sahip olurken sınırları belirleyenler ise \%100 etkinliğe sahip olmaktadır. Bilimsel araştırmalarda da bu durum göz önünde bulundurularak gerekli yorumlamalar yapılmaktadır. Bu çalışmada VZA kullanıldığından dolayı temel bileşenleri olan etkinlik, etkinlik sınırı, karar verme birimleri vb. bu şekilde açıklanabilir.

Literatürde ise VZA'nın hem teoride hem de uygulamada yaygın kullanılması birçok araştırmanın kullandığı yöntem olarak karşımıza çıkmaktadır. Aynı zamanda yerli ve yabancı birçok araştırmacının çalışma konusunu oluşturmaktadır. 
Tablo 1:Geçmiş Yıllarda Yapılan Çalışmalar

\begin{tabular}{|c|c|c|c|c|}
\hline Araştırmalar & Dönem Aralığı & Oluşturulan Örneklem & Girdi & Çıktı \\
\hline Çiftçi (2004) & $1998-2002$ & $\begin{array}{l}\text { Hayat ve hayat dışı } \\
\text { faaliyet gösteren } 62 \text { sigorta } \\
\text { şirket }\end{array}$ & $\begin{array}{l}\text { - acente sayıs1 } \\
\text { - personel sayı11 } \\
\text { - sabit varlıklar } \\
\text { - özkaynaklar }\end{array}$ & $\begin{array}{l}\text { - prim üretim miktarı } \\
\text { - teknik karlılık }\end{array}$ \\
\hline Altan (2010) & $2005-2007$ & $\begin{array}{l}\text { Hayat dışı alanında faaliyet } \\
\text { gösteren } 25 \text { sigorta şirketi }\end{array}$ & $\begin{array}{l}\text {-Nakit ve nakit benzeri } \\
\text {-maddi varlıklar } \\
\text {-finansal varlıklar ile } \\
\text { riski } \\
\text { sigortaya ait finansal } \\
\text { yatırımlar } \\
\text {-esas faaliyetlerden } \\
\text { borçlar } \\
\text {-sigortacılık teknik } \\
\text { karş1lkkları } \\
\text {-ödenmiş sermaye }\end{array}$ & $\begin{array}{l}\text {-dönem net kâr (+) } \\
\text { /zarar }(-) \\
\text {-esas faaliyetlerden } \\
\text { alacaklar }\end{array}$ \\
\hline $\begin{array}{l}\text { Bülbül ve } \\
\text { Akhisar } \\
(2005)\end{array}$ & $1999-2003$ & $\begin{array}{l}\text { Hayat dişı alanında faaliyet } \\
\text { gösteren } 30 \text { sigorta şirketi }\end{array}$ & $\begin{array}{l}\text {-özkaynaklar/ } \\
\text { aktif toplamı } \\
\text {-öz kaynaklar/ teknik } \\
\text { karş1lıklar } \\
\text { - likit aktifler/likit } \\
\text { toplamı } \\
\text { - hasar pirim oranı } \\
\text {-konservasyon oranı }\end{array}$ & $\begin{array}{l}\text { - teknik kar/alınan } \\
\text { primler } \\
\text { - mali kar/alınan } \\
\text { primler } \\
\text { - bilanço karı/ alınan } \\
\text { primler } \\
\text {-teknik kar/bilanço karı }\end{array}$ \\
\hline Kayalı (2007) & $2000-2006$ & $\begin{array}{l}\text { Her y1l farklı sayıda hayat ve } \\
\text { hayat dışı alanında faaliyet } \\
\text { gösteren sigorta şirketi }\end{array}$ & $\begin{array}{l}\text { - personel sayısı } \\
\text { - acente sayısı } \\
\text { - sabit değerler } \\
\text { - likit değerler } \\
\text { - teknik karş1lıklar } \\
\text { - özkaynaklar } \\
\text { - aktif toplamı } \\
\end{array}$ & $\begin{array}{l}\text { - toplam prim üretimi } \\
\text { - teknik kar } \\
\text { - mali gelir }\end{array}$ \\
\hline Dalkılıç (2012) & $2008-2010$ & $\begin{array}{l}\text { Hayat dişı alanda } \\
\text { gösteren sigorta şirketi }\end{array}$ & $\begin{array}{l}\text {-özkaynak } \\
\text {-çalışan sayısı } \\
\text {-acente sayısı } \\
\text {-sabit varlıklar }\end{array}$ & $\begin{array}{l}\text {-toplam sigortacılık } \\
\text { teknik karşıllkları (net) } \\
\text {-toplam prim üretimleri } \\
\text {-ödenen tazminatlar } \\
\text { toplamı (net) }\end{array}$ \\
\hline $\begin{array}{l}\text { Kilıçkaplan } \\
\text { ve Karpat } \\
\text { (2004) }\end{array}$ & $1998-2002$ & $\begin{array}{l}\text { Her yıl farklı sayıda hayat } \\
\text { alanında faaliyet gösteren } \\
\text { sigorta şirketi }\end{array}$ & $\begin{array}{l}\text { - personel ve yönetim } \\
\text { giderleri } \\
\text { - sabit varlıklar } \\
\text { - özkaynaklar }\end{array}$ & $\begin{array}{l}\text { - alınan primler } \\
\text { - teknik kâr/zarar } \\
\text { - mali kâr/zarar }\end{array}$ \\
\hline $\begin{array}{l}\text { Başkaya ve Akar } \\
(2005)\end{array}$ & 2003 & $\begin{array}{l}12 \text { sigorta şirketi analiz } \\
\text { edilmiştir. }\end{array}$ & $\begin{array}{l}\text {-acente sayısı } \\
\text {-banka şubesi sayısı } \\
\text {-çalışan sayısı } \\
\end{array}$ & $\begin{array}{l}\text {-poliçe adedi } \\
\text {-prim tutarı }\end{array}$ \\
\hline Diboky ve Ubl (2007) & $2002-2005$ & $\begin{array}{l}\text { Almanya'da faaliyet gösteren } \\
356 \text { adet sigorta şirketi ( } 73 \\
\text { mütüel, } 263 \text { anonim ve } 20 \text { tanesi } \\
\text { kamu şirketi) analiz edilmiştir. }\end{array}$ & $\begin{array}{l}\text {-emek } \\
\text {-işletme sermayesi } \\
\text {-finansal borç } \\
\text { özkaynak }\end{array}$ & -net gelir \\
\hline Luhnen (2009) & $1995-2006$ & $\begin{array}{l}\text { Almanya'da faaliyet gösteren } \\
\text { hayat diş1 sigorta şirketleri }\end{array}$ & $\begin{array}{l}\text {-emek ve işletme } \\
\text { hizmetleri } \\
\text {-borç sermayesi } \\
\text {-özkaynaklar }\end{array}$ & $\begin{array}{ll}\text {-gerçekleşen } & \text { net } \\
\text { tazminatlar } & \\
\text {-yatırım varlıkları } & \end{array}$ \\
\hline
\end{tabular}

Çiftçi (2004), CCR ve BCC modelleri ile VZA yöntemi kullanarak, hayat dışı branşlarda faaliyet gösteren 41 sigorta şirketlerinden 11'i etkin 30 etkin olmadığ 1 sonucuna varmıştır. Hayat branşında faaliyet gösteren Sigorta Şirketlerinin Sabit Ölçek Varsayımı altında CCR DEA Analizi sonucu 9 sigorta şirketinin etkin 12 tanesinin etkin faaliyette bulunmadığ 1 tespit edilmiştir (Çiftçi, 2004: 135).

Altan (2010), yaptığı çalışmada hayat dışı sigorta şirketlerinin 2005-2007 yılları arasında büyük çoğunluğunun etkinlik sınırına ulaşamadı sonucuna ulaşmıştır. 
Bülbül ve Akhisar (2005), hayat dışı alanında faaliyet gösteren 30 sigorta şirketinin etkinliklerini ölçmesi sonucunda şirketlerin büyük çoğunluğunun etkinlik sınırına ulaşamadıkları sonucuna ulaşılmıştır. Şirketler için belli başlı iyileştirme oranları belirlenmiştir.

Kayalı (2007), yaptığ1 çalışmada 2000-2006 döneminde Türk sigorta şirketlerinin 2001, 2004 ve 2006 yıllarındaki teknik etkinsizliğin temel kaynağının saf teknik etkinsizlik olması, mevcut prim üretiminin optimum girdi miktarlarıyla üretilmediğini göstermektedir. 2002, 2003 ve 2005 yıllarında ise sektörün teknik etkinsizliğinin nedeninin ölçek etkinsizliği olması, sigorta şirketlerinin prim üretimi bakımından uygun olmayan ölçekte (kapasitede) faaliyet göstermedikleri anlamına geldiği sonucuna ulaşmıştır (Kayalı, 2007: 113).

Dalk1lıç (2012), hayat dışı alanında faaliyet gösteren 27 sigorta şirketinden 2008 y1lında 17'sinin etkin olduğu, 10 tanesinin ise etkin olmadığı sonucuna ulaşmıştır. 2008 yılında sigorta şirketlerinin tümü değerlendirildiğinde \%63'ünün etkin olduğu gözlenmiştir. 2009 y1lında 27 sigorta şirketinden 21 tanesi etkindir ve 3 şirket etkin değildir. 2009 yılında genel sonuçlara bakıldığında $\% 78$ etkinlik yüzdesi ile etkinlik en üst seviyeye ulaşılmıştır. Son olarak 2010 yılında ise 27 sigorta şirketinin 13'ü etkin iken, 14'ü etkin değildir ve sonuç olarak da etkinlik yüzdesi \%48 olduğu tespit edilmiştir.

Kılıçkaplan ve Karpat (2004), çalışmasında 1998 ve 2002 yılları arasında Türkiye'deki hayat sigortası sektöründe faaliyet gösteren çeşitli büyüklükteki firmaların teknik, saf ve ölçek etkinliklerini araştırmıştır (Kıllçkaplan ve Karpat, 2004: 1).

Başkaya ve Akar (2005), çalışma sonucunda incelenen 12 sigorta şirketinden 6 tanesi tam etkin olarak bulunmuş, tam etkin olmayan diğer 6 şirket için de referans kümeleri ve potansiyel iyileştirme tabloları oluşturulmuştur (Başkaya ve Akar, 2005: 49).

Diboky ve Ubl (2007), çalışmasında 2002-2005 yılları arasında Almanya'da faaliyet gösteren 73 mütüel şirket, 20 kamu şirketi ve 263 anonim şirketi olmak üzere toplamda 356 adet sigorta şirketini analiz etmişlerdir. Girdi olarak emek, işletme sermayesi, finansal borç ve özkaynak; çıktı olarak da net gelir kullanmışlardır (Diboky ve Ubl, 2007; 15).

Luhnen (2009), çalışmasında 1995-2006 yılları arasında Malmquist Toplam Faktör Verimliliği endeksini kullanarak, Almanya'da faaliyet gösteren 295 adet hayat dışı sigorta şirketinin etkin olup olmadığını VZA ile değerlendirilmiştir. Sonucunda sigorta şirketlerinin yaklaşı olarak \%20' sinin teknik etkinliği, \%50' sinin ise maliyet etkinliği olduğu saptanmıştır (Luhnen, 2009; 501).

Yapılan araştırmaların yayınlanma zamanları farklılık göstermektedir. Bunun dışında ele alınan dönem aralıklarının farklı olması, girdi ve çıktı içeriğinin değişiklik göstermesi bu iki faktöre ilave olarak ülke bazında farklılaşmaların olması sebebiyle sonuçlar da birbirinden bağımsız olmaktadır. Aynı zamanda oluşturulan örneklemlerin hayat, hayat dişı ve emeklilik gibi segmentlere ayrılması bir diğer farklılık olarak göze çarpmaktadır. Bu durumda elde edilen sonuçlar da değişiklik gösterecektir. Tek ortak noktaları sigorta şirketlerinin etkinliği üzerine yapılan bütün çalışmaların amaca uygun olarak hareket edilmesi durumudur.

\section{YÖNTEM}

Performans, verimlilik ve etkinlik kavramları birimlerin varlıklarını idame ettirebilmeleri açısından önem taşımaktadır. Kavramların taşıdığı özellikler nedeniyle gerekli analizlerin yapılması ile güçlü ve zayıf yönlerin ortaya çıkarılması sağlanır. Ölçme olmadan neyin iyi neyin kötü olduğuna, neye ve kime göre iyi ya da kötü olduğuna karar vermek mümkün değildir (Yeşilyurt, 2009: 135). Bu yüzden performans, verimlilik ve etkinlik kavramları gerekli analizlerin yapılması ve yorumlanması açısından ne anlama geldiğinin bilinmesi gerekmektedir.

Performans, bir işi yapan bireyin veya grubun o işle amaçlanan hedefe yönelik olarak, nereye varabildiği, neyi sağlayabildiğinin ifadesidir. Performansın tanımlanmasında nerede olduğumuz, ne kadar iyi olabildiğimiz ve nerede olmamız gerektiği soruları yer almaktadır (Kutlar ve Kartal, 2004: 51).

Verimlilik, sahip olduğumuz kaynakların doğru ve etkin bir biçimde kullanılmasını sağlamak, performans ve yararlılıklarını en üst düzeye çıkartabilmek demektir. İşletme bütün enerji kaynaklarını etkin bir biçimde değerlendirmelidir (Özsever, 2009: 45).

Etkinlik ise işletmecilik yönüyle örgütlerin belirlenmiş amaçlarına ulaşmak amacıyla gerçekleştirdikleri faaliyetlerin sonucunda, bu amaçlara ulaşma derecesini belirleyen bir performans ölçütüdür (Altan, 2010: 185).

Açıklanan bu kavramların bu derece önemli olması birtakım yöntemlerin geliştirilmesinde etkili olmuştur. Etkinlik ve verimlilik ile ilgili olarak yapılan analizler üç ana başlık altında toplanmaktadır. Oran analizi, parametreli yöntemler ve parametresiz yöntemler olarak tanımlanan bu yöntemler uygulanış ve değerlendirme süreçleri bakımından birbirlerinden farklı yapı ve özelliklere sahiptir (Akyüz vd., 2015: 24). 
Oran analizinde bir tek girdinin ve çıktının oranı şeklinde tanımlanan bir oranın süreç içerisinde izlenmesi şeklinde uygulanır (Koçak ve Çilingirtürk, 2011: 167). Oran analizi yönteminin yaygın olarak kullanılmasının sebepleri; uygulanması ve yorumlanmasındaki kolaylıklar, daha az bilgi ve daha az veri ile analiz yapılmasına imkân tanımasıdır (Şahin, 2012: 129).

Parametrik yöntemlerde etkinlik ölçümü gerçekleştirilecek işletmelerin girdileri ile çıktıları arasında fonksiyonel bir ilişki olduğu varsayımı yapılır ve bu fonksiyonun parametrelerinin tahmin edilmesine çalışılır (Sarı, 2015: 5).

Parametresiz yöntemler ise çok girdi ve çok çıktıyı işleyecek yetenektedir ve doğrusal form dışında, girdi ve çıktıları ilişkilendiren bir fonksiyonel forma ihtiyaç duymazlar. Verimlilik ölçümü ortalama değere göre değil tam verimliliğe sahip olanlarla kıyaslanarak yapılır. Çok sayıda girdi ve çıktının bir arada değerlendirilmesini olanaklı kılar ve veriler üzerinde çeşitli varsayımlar kullanmaya ve dönüşümler yapmaya gerek bulunmamaktadır (Şahin, 2008: 14). Parametresiz yöntemler literatürde Veri Zarflama Analizi ve Serbest Atılabilir Zarf Modeli olmak üzere iki kısımda yer alır. Bu çalışmada sadece Veri Zarflama Analizi yönteminden bahsedilecektir.

Veri zarflama analizinin matematiksel yapısı ilk olarak Charnes, Cooper ve Rhoders tarafindan kesirli programlama modeli olarak 1978 de ortaya atılmıştır (Charnes vd., 1978: 431-432). Veri Zarflama Analizi (VZA); doğrusal programlamanın özel bir uygulama şekli olup, aynı amaç ve hedeflere sahip işletmelerin göreceli olarak verimliliğini ölçmede kullanılan bir yöntemdir (Tetik, 2003: 222). Özellikle, birden fazla girdi ya da çıktının, ağırlıklı bir girdi ya da çıktı setine dönüştürülemediği durumlarda VZA etkin bir yaklaşım olarak kabul görmüştür (Ulucan, 2000: 406-407). Kısacası VZA, uzmanlar tarafindan yaygın olarak kullanılan, girdi-çıktı verimliliğini ölçmek için uygun bir yaklaşımdır (Lita, 2018: 250).

Çeşitli bağlamlarda, birçok ülkede faaliyet gösteren, farklı türdeki kurumların performansının değerlendirilmesinde VZA uygulamalarının kullanıldığı görülmüştür. Bu uygulamalar eğitim, bankacılık, sağl1k hatta imalat ve ormanc1lık sektöründe kendini göstermektedir.

Charnes vd.(1978), benzer girdiler kullanarak benzer çıktılar üreten, girdiyi çıktıya dönüştürmekten sorumlu birimlere "Karar Verme Birimi (Desicion Making Unit)" adını vermişlerdir. Bu karar verme birimleri kurum, şirket, firma, bölüm, işletme, üniversite olabildiği gibi tek bir kuruma ait girdi ve çıktıları gösteren yıl değerleri de olabilir (Kaynar vd., 2005: 38). İncelemeye alınan karar birimlerinin temelinde en az girdi ile en çok çıktı bileşimini elde etme durumu söz konusudur. Bu sayede en iyi karar birimleri oluşturularak etkinlik sınırına göre analizi gerçekleştirilecektir.

Temel VZA modelleri; toplamsal model, çarpımsal model, CCR ve BCC modelleri olmak üzere dört ayrı grupta sınıflandırılabilir (Bakırcı ve Babacan, 2010: 218). Yapılan çalışmaların genelinde CCR ve BCC modelleri kullanıldığından dolayı bu çalışmada da iki model hakkında bilgi verilecektir.

VZA başlığı altında oluşturulan modellerin temelinde ölçeğe göre sabit ve değişken getiri yer almaktadır. Bununla beraber yönelimlerine göre girdi yönelimli, çıktı yönelimli ve yönelimsiz olmak üzere değişkenlik göstermektedir. Girdi odaklılık, çıktı miktarının sabit tutularak girdi miktarındaki değişikliklere göre analiz edilmesidir. Çıktı odaklılık ise, girdi miktarının sabit tutularak, çıktı miktarındaki değişime göre analiz edilmesidir (Şahin, 2012: 139).

CCR modeli; VZA' nin ilk modeli olup Charnes, Cooper ve Rhodes tarafindan geliştirilmiştir. Bu model, ölçeğe göre sabit getiri varsayımı altında karar birimlerinin toplam etkinlik skorlarını hesaplamaktadır (Behdioğlu ve Özcan, 2009: 305). Bir karar biriminin hem teknik etkinliği, hem de ölçek etkinliğini yakalaması durumu ise toplam etkinlik olarak adlandırılmaktadır. Bu durumda;

Toplam etkinlik $=$ Teknik Etkinlik * Ölçek etkinliği

olarak formülize edilebilir (Aslan, 2007: 385-386).

VZA' nde temel etkinlik ölçütü, çıktıların ağırlıklı toplamının girdilerin ağırlıklı toplamına oranlanmasiyla bulunur. Formülize edilirse;

$\underline{u_{1} y_{1}+u_{2} y_{2}+\cdots+u_{n} y_{n}}$

$\overline{v_{1} x_{1}+v_{2} x_{2}+\cdots+v_{m} x_{m}}$

olarak hesaplanır. Formülde j. karar noktası için $\mathrm{m}$ adet girdi ve $\mathrm{n}$ adet çıktı vardır ve yine formüle bakılacak olursa, $u_{n} n$. çıktının ağırlığını, $y_{n} n$. çıktının miktarını, $v_{m} m$. girdinin ağırlığını ve $x_{m} m$. girdinin miktarını göstermektedir.

CCR modeli $\mathrm{m}$ adet girdi ve $\mathrm{n}$ adet çıktı varsayımı adı altında etkin sınırı ve bu etkin sınır üzerinde yer almayan noktaların merkeze olan uzaklıklarının belirlenmesinde kullanılan bir yöntem olarak karşımıza çıkmaktadır. Burada j. karar biriminin etkinliği $h_{j}$ ise, elde edilecek olan değerin maksimize edilmesi gerekecektir. Matematiksel ifadesi şu şekildedir:

$$
\operatorname{Enbh}_{\mathrm{j}}=\frac{\sum_{r=1}^{n} u_{r} y_{r}}{\sum_{i=1}^{m} v_{i} x_{i}}
$$


Kısıtlar ise şu şekilde gösterilir:

$\frac{\sum_{r=1}^{n} u_{r} y_{r}}{\sum_{i=1}^{m} v_{i} x_{i}} \leq 1$

$u_{r} \geq 0$

$v_{i} \geq 0$

Kesirli programlamanın çözümü doğrusal programlamaya göre zor olduğundan formülde birtakım değişiklikler yapılması gerekecektir. $O$ halde aşağıdaki formüller elde edilir:

$$
\begin{gathered}
\text { Enbh }_{j}=\sum_{r=1}^{n} u_{r} y_{r} \\
\sum_{i=1}^{m} v_{i} x_{i}=1 \\
\sum_{r=1}^{n} u_{r} y_{r}-\sum_{i=1}^{m} v_{i} x_{i} \geq 0 \\
u_{r}, v_{i} \geq 0
\end{gathered}
$$

Buraya kadar olan formüller girdi odaklılık durumu üzerine düzenlenmiştir. Çıktı odaklılık durumu dikkate alınarak çözülecekse şu şekilde olacaktır:

$$
\begin{aligned}
& \text { Enkg }_{\mathrm{j}}=\sum_{i=1}^{m} v_{i} x_{i} \\
& \sum_{r=1}^{n} u_{r} y_{r}=1 \\
& -\sum_{r=1}^{n} u_{r} y_{r}+\sum_{i=1}^{m} v_{i} x_{i} \geq 0 \\
& u_{r}, v_{i} \geq 0
\end{aligned}
$$

BCC modeli, Banker, Charnes ve Cooper tarafindan geliştirilmiş olup CCR modelinin varsayımlarında değişiklik yapılarak oluşturulmuş bir modeldir. BCC modeli kullanılarak tüm karar birimleri için ölçeğe göre getiri tipi de belirlenebilir. BCC sınırı daima CCR sınırının altında yer alır. Bu nedenle CCR etkinlik skoru BCC etkinlik skorundan küçük veya ona eşit olmaktadır (Dinçer, 2008: 834). BCC ile CCR arasındaki tek fark, $\lambda$ değerinin toplamının 1'e eşit olması durumudur. $\lambda$ değeri, etkin olmayan karar noktasında etkin girdi bileşimini oluşturmak için gerekli olan bilgiyi sağlayan değerdir. Matematiksel ifadesi ise şu şekildedir:

$$
\begin{aligned}
& \text { Amaç fonksiyonu, } \\
& \text { Enk } \Theta_{\mathrm{k}} \\
& \text { Kisitlar, } \\
& \sum_{j=1}^{N} y_{r j} \lambda_{j k} \geq y_{r k} \\
& \Theta_{k} x_{i k}-\sum_{j=1}^{N} x_{i j} \lambda_{j k} \geq 0 \\
& \sum_{j=1}^{N} \lambda_{j}=1
\end{aligned}
$$

Araştırmada kullanılan bir diğer yöntem ise Malmquist Toplam Faktör Verimliliği (TFV) Endeksidir. Malmquist (1953) tarafından geliştirilen uzaklık (distance) fonksiyonlarına dayalı olarak ifade edilen bu endeks, her bir veri noktasının ortak teknolojiye göre nispî uzaklık oranlarını hesaplayarak, iki veri noktası arasındaki toplam faktör verimliliğindeki değişmeyi ölçer (Deliktaş, 2002: 252). Malmquist verimlilik endeksi, özellikle parametrik olmayan spesifikasyonlar mikro verilere uygulandığında zaman içindeki verimlilik ölçümünde standart yaklaşım haline gelmiştir (Bjurek, 1996: 303).

$\mathrm{D}_{\mathrm{o}}^{\mathrm{t}}(\mathrm{x}, \mathrm{y}), \mathrm{t}+1$ dönemi gözleminin $\mathrm{t}$ dönemi teknolojisinden olan uzaklığını ifade eder. Eğer $m_{o}$ fonksiyonunun değeri 1.0' dan büyükse $t$ döneminden $t+1$ dönemine $T F V^{\prime}$ de büyüme olduğunu gösterir. 1.0'dan az olması durumunda ise aynı dönemler dikkate alındığında TFV' de bir düşüş olduğunu ifade eder. $\mathrm{Bu}$ denklem şu şekilde ifade edilebilir;

$$
\mathrm{M}_{0}\left(\mathrm{y}^{\mathrm{t}}, \mathrm{x}^{\mathrm{t}}, \mathrm{y}^{\mathrm{t}+1}, \mathrm{x}^{\mathrm{t}+1}\right)=\frac{d_{0}^{t+1}\left(y^{t+1}, x^{t+1}\right)}{d_{0}^{t}\left(y^{t}, x^{t}\right)} \times\left[\frac{d_{0}^{t}\left(y^{t+1}, x^{t+1}\right)}{d_{0}^{t}\left(y^{t}, x^{t}\right)} \times \frac{d_{0}^{t+1}\left(y^{t+1}, x^{t+1}\right)}{d_{0}^{t}\left(y^{t}, x^{t}\right)}\right]^{1 \backslash 2}
$$

Formülde çarpı işaretinden bir önceki kısım $t$ ve $t+1$ yılları arasındaki çıktı eksenli teknik etkinlik değişimini ölçmektedir. Sonraki kısım ise teknolojide meydana gelen değişimleri ölçmektedir. Bu durumda;

$\mathrm{M}_{0}\left(\mathrm{y}^{\mathrm{t}}, \mathrm{x}^{\mathrm{t}}, \mathrm{y}^{\mathrm{t}+1}, \mathrm{x}^{\mathrm{t}+1}\right)=\mathrm{TED} \times \mathrm{TD}$ olarak da ifade edilebilir.

\section{ANALIZ VE BULGULAR}

Analiz, ölçeğe göre sabit getiri varsayımı altında DEA (Data Envelopment Analysis-Veri Zarflama Analizi) yöntemi ve DEAP 2.1. paket programı kullanılarak yapılmıştır. Bu çalışmada kurulan model, girdiye yönelik, ölçeğe göre sabit odaklı ve çok aşamalı DEA yöntemi şeklinde olmuştur. Çalışmada 20142017 yılları arası kesintisiz veriye sahip olan 23 hayat dışı sigorta şirketi analize tabi tutulmuştur. $\mathrm{Bu}$ şirketlerin yıllar itibariyle etkinlik değerleri ve son yılın etkinlik skorlarının potansiyel iyileştirme değerleri Veri Zarflama Analizi yardımıyla tespit edilerek tablolar halinde gösterilmiştir. Ardından Malmquist Toplam Faktör Verimliliği Endekslerinden yararlanarak şirketlerin yıllar itibariyle gösterdikleri gelişimler hesaplanarak tablo haline getirilmiş ve yorumlanmıştır. 
Çalışmanın uygulama kısmında kullanılan Veri Zarflama Analizi'nin ilk adımı karar birimlerinin seçilmesidir. İkinci adım ise kullanılacak girdi ve çıktıların tespit edilmesidir. Ardından program sonuçlarına göre yıllar itibariyle etkinlik değerleri bulunmalıdır. Son yıl olan 2017 yılının etkinlik değerlerinin potansiyel iyileştirme tablosunun oluşturulmasının ardından aynı çıktı düzeyine en uygun girdi seviyesi belirlenmelidir. Son aşama ise Malmquist Toplam Faktör Verimliliği Endeksleri yardımıyla, analizin olduğu bu 4 yıllık süreçte, karar birimleri olan bu 23 firmanın etkinlik değerleri açısından yıllar itibariyle gösterdikleri performans incelenmiş ve yorumlanmıştır.

\subsection{Karar Birimlerinin Seçilmesi}

Uygulama kısmında Veri Zarflama Analizinin yanı sıra Malmquist Toplam Faktör Verimliliği Endeksi de kullanılacağı için analize dahil edilecek firmaların analiz dönemi boyunca kesintisiz veriye sahip olmaları gerekmektedir. Analizde karar alma probleminde başarılı sonuçlar alınabilmesi için girdi ve çıktı sayısının olabildiğince çok olması gerekmektedir. Ancak seçilen girdi ve çıktı elemanlarının tümü her karar birimi için kullanılmak zorundadır. Bir Veri Zarflama modeli için seçilen girdi sayısı (m) ve çıktı sayısı (p) ise en az $(\mathrm{m}+\mathrm{p}+1)$ tane karar birimi araştırmanın güvenirliliği açısından gerekli bir kısıt olarak ortaya çıkmaktadır. Ayrıca, karar alma birimi sayısı değişken sayısının en az iki katı olmalıdır (Çolak ve Altan, 2002: 44-45).

Çalışmada uygulanan modelde 3 girdi ve 1 çıktı değişkeni kullanıldığı için karar birimleri sayısının en az;

Girdi Sayısı + Çıktı Sayısı $+1=6$ ve (Girdi Sayısı + Çıktı Sayısı) x $2=10$ olması gerekmektedir.

$\mathrm{Bu}$ noktadan hareketle Türkiye'de faaliyet gösteren ve 2014-2017 yılları arası kesintisiz veriye sahip hayat dışı sigorta şirketlerinden 23 tanesi belirlenerek çalışmaya dahil edilmiştir. Tablo: 1'de analize dahil edilen sigorta şirketleri verilmiştir.

Tablo 2: 2014-2017 Yıllarına Ait Sigorta Şirketleri ve Kodları

\begin{tabular}{|l|l|l|l|}
\hline Şirket Kodu & Şirket Ad1 & Şirket Kodu & Şirket Ad1 \\
\hline B1 & AKSİGORTA & B13 & HDI \\
\hline B2 & ALLIANZ & B14 & KORU \\
\hline B3 & ANADOLU & B15 & LİBERTY \\
\hline B4 & AXA & B16 & *MAPFRE GENEL \\
\hline B5 & DOĞA & B17 & NEOVA \\
\hline B6 & DUBAİ STAR & B18 & RAY \\
\hline B7 & ERGO & B19 & SBN \\
\hline B8 & EUREKO & B20 & SOMPO JAPAN \\
\hline B9 & GENERALİ & B21 & TÜRK NIPPON \\
\hline B10 & GROUPAMA & B22 & ZİRAT \\
\hline B11 & GÜNEŞ & B23 & ZURICH \\
\hline B12 & HALK & & \\
\hline
\end{tabular}

*Mapfre Genel Sigorta, Ekim 2016 tarihinden itibaren Mapfre Sigorta olarak faaliyetlerini sürdürmeye devam etmiştir.

\subsection{Girdi ve Çıktıların Belirlenmesi}

Karar birimlerinin seçimi gibi girdi çıktı değişkenlerinin belirlenmesi de parametrik olmayan etkinlik analizlerinde son derece önemlidir. Zira kullanılacak girdi ve çıktıların isabetli bir şekilde tespit edilmesi, uygulamanın güvenilirliğini ve geçerliliğini artırması açısından ve etkin olmayan karar birimlerine önerilecek iyileştirmelerin ne şekilde ve nasıl yapılacağı konusunda daha doğru yönlendirme sağlaması açısından büyük önem taşımaktadır (Şahin, 2012: 164).

Kullanılan girdi ve çıktıların seçiminde bir yandan yazındaki çalışmalardan yararlanılırken, diğer taraftan sigortacılık sektörü açısından önemli olduğu düşünülen faktörler de göz önünde bulundurulmuştur.

Araştırmada kullanılan veriler T.C. Hazine ve Maliye Bakanlığı tarafindan yayımlanmakta olan 20142017 yıllarına ait Sigortacılık ve Bireysel Emeklilik Faaliyet Raporları bölümünden oluşturulmuştur. Araştırmada kullanılan nakit ve nakit benzerleri değerler şirketlerin kasa, banka ve diğer gelirlerin toplamını ifade etmektedir. Esas faaliyetten borçların altında sigortacılık ve reasürans faaliyetlerinden borçlar, sigortacılık\reasürans şirketlerinden alınan depolar, emeklilik faaliyetlerinden borçlar ve diğer esas faaliyetlerden borçlar yer almaktadır. Sigortacılık teknik karşılıkları (net) ise kazanılmamış primler, devam eden riskler, matematik, muallak tazminat, ikramiye-indirimler ve diğer teknik karşılıklarından oluşmaktadır. Ödenmiş sermaye ise nominal sermaye ve ödenmiş sermaye ile sermaye düzeltmesi net farklarından oluşturulmuştur. Esas faaliyetten alacaklar kalemi sigortałreasürans faaliyetten alacaklar, sigortałreasürans 
şirket nezdinde depolar, sigortalılara krediler, emeklilik faaliyetinden alacaklar ve esas faaliyetten kaynaklanan şüpheli alacaklardan oluşmaktadır.

Girdi ve çıktı değişkenleri tablo halinde şu şekilde düzenlenebilir:

\section{Tablo 3: Analizde Kullanılacak Girdi ve Çıktı Değişkenleri}

\begin{tabular}{|l|l|}
\hline & GİRDİ DEĞİŞKENLERİ \\
\hline G1 & Nakit ve Nakit Benzerleri \\
\hline G2 & Esas Faaliyetten Borçlar \\
\hline G3 & Sigortacılık Teknik Karşılıkları (Net) \\
\hline G4 & Ödenmiş Sermaye \\
\hline & ÇIKTI DEĞİŞKENLERİ \\
\hline Ç1 & Esas Faaliyetten Alacaklar \\
\hline
\end{tabular}

Belirlenen girdilere ve çıktıya göre sigorta şirketlerinin etkin çalışıp çalışmadıkları analiz edilecektir. Öncelikle firmaların etkinlik skorları bulunarak hangi firmaların tam etkin oldukları, hangi firmaların ise etkin olmadıkları tespit edilecektir. Bu aşamadan sonra analizin son yılı için tam etkin firmaların referans gösterilme sayıları ve etkin olmayan firmaların potansiyel iyileştirme tabloları hazırlanarak hedef değerlere ulaşmaları için yol gösterilecektir. Ardından firmaların yıllar itibariyle gerçekleştirdikleri gelişmeleri görebilmek için Malmquist Toplam Faktör Verimliliği Endeksleri’nden yararlanılmıştır.

\subsection{Bulgular}

Tablo 4: Gözlem Kümesi İçin Etkinlik Değerleri (2014-2017)

\begin{tabular}{|c|c|c|c|c|c|}
\hline Kodu & Firmalar & $\begin{array}{l}2014 \text { Yılı } \\
\text { Teknik } \\
\text { Etkinlik }\end{array}$ & $\begin{array}{l}2015 \text { Yılı } \\
\text { Teknik } \\
\text { Etkinlik } \\
\end{array}$ & $\begin{array}{l}2016 \text { Yılı } \\
\text { Teknik } \\
\text { Etkinlik }\end{array}$ & $\begin{array}{l}\text { 2017Yılı } \\
\text { Teknik } \\
\text { Etkinlik }\end{array}$ \\
\hline 1 & AKSİGORTA & 0.744 & 0.872 & 0.695 & 0.612 \\
\hline 2 & ALLIANZ & 0.900 & 0.974 & 0.496 & 0.994 \\
\hline 3 & ANADOLU & 0.769 & 0.835 & 0.573 & 0.629 \\
\hline 4 & AXA & 0.974 & 1.000 & 0.555 & 1.000 \\
\hline 5 & DOĞA & 0.461 & 0.793 & 0.577 & 1.000 \\
\hline 6 & DUBAİ STAR & 1.000 & 1.000 & 1.000 & 1.000 \\
\hline 7 & ERGO & 1.000 & 0.972 & 0.584 & 1.000 \\
\hline 8 & EUREKO & 1.000 & 1.000 & 1.000 & 1.000 \\
\hline 9 & GENERALİ & 0.661 & 0.496 & 0.546 & 0.585 \\
\hline 10 & GROUPAMA & 0.993 & 0.838 & 0.494 & 0.753 \\
\hline 11 & GÜNEŞ & 1.000 & 1.000 & 0.756 & 0.686 \\
\hline 12 & HALK & 0.420 & 0.667 & 0.436 & 0.379 \\
\hline 13 & HDI & 0.761 & 0.809 & 0.702 & 0.834 \\
\hline 14 & KORU & 0.371 & 0.318 & 1.000 & 1.000 \\
\hline 15 & LİBERTY & 0.810 & 0.749 & 0.606 & 1.000 \\
\hline 16 & MAPFRE GENEL & 1.000 & 1.000 & 0.840 & 0.794 \\
\hline 17 & NEOVA & 1.000 & 1.000 & 1.000 & 0.721 \\
\hline 18 & RAY & 0.743 & 0.784 & 0.671 & 0.682 \\
\hline 19 & SBN & 0.350 & 0.548 & 0.306 & 0.298 \\
\hline 20 & SOMPO JAPAN & 0.861 & 1.000 & 0.360 & 0.377 \\
\hline 21 & TÜRK NIPPON & 1.000 & 1.000 & 0.454 & 0.725 \\
\hline 22 & ZİRAAT & 0.453 & 0.650 & 0.518 & 0.548 \\
\hline \multirow[t]{2}{*}{23} & ZURİCH & 0.432 & 0.468 & 0.308 & 0.319 \\
\hline & Ortalama & $\mathbf{0 . 7 7 0}$ & 0.816 & 0.629 & 0.736 \\
\hline
\end{tabular}

Tablo 3'te görüldüğ̈̈ gibi tam etkin bir firmanın etkinlik değerleri 1.000 olmaktadır. Dubai Star ve Eureko firmaları 2014 ve 2017 yıllarını kapsayan dört yılda da tam etkinlik göstermişlerdir. Neova firması ise 2014, 2015 ve 2016 yıllarında tam etkin iken son yıl olan 2017'de etkinlik değerini düşürmüştür. 
Tablo 5: Yıllar İtibariyle Ortalama İstatistikler

\begin{tabular}{|l|c|c|c|c|}
\hline & $\mathbf{2 0 1 4}$ & $\mathbf{2 0 1 5}$ & $\mathbf{2 0 1 6}$ & $\mathbf{2 0 1 7}$ \\
\hline Ortalama Etkinlik Derecesi & 0.770 & 0.816 & 0.629 & 0.736 \\
\hline $\begin{array}{l}\text { Gözlem Kümesini Oluşturan } \\
\text { Firma Sayı1 }\end{array}$ & 23 & 23 & 23 & 23 \\
\hline Etkin Birim Sayıs1 & 7 & 8 & 4 & 7 \\
\hline En Düşük Etkinlik Derecesi & 0.350 & 0.318 & 0.306 & 0.298 \\
\hline
\end{tabular}

Tablo 4'te sırasıyla gözlem kümesini oluşturan firmaların yıllar itibariyle ortalama etkinlik dereceleri, toplam firma sayıları, etkin firma sayıları ve son olarak ta en düşük etkinlik dereceleri gösterilmiștir. Buna göre 2014 yılının ortalama etkinlik değeri 0.770 olurken, 2015 yılında 0.816, 2016 yılında 0.629 ve 2017 yılında 0.736 olarak gerçekleşmiştir. Görüldüğü gibi 2015 yılının ortalama etkinlik değeri bir önceki yıla göre artış gösterirken, 2016 yılında bu değer düşmüş, son yılda ise artış göstererek 0,736 değerine ulaşmıştır. Araştırmanın geçerli olduğu tüm yıllarda gözlem kümesini oluşturan firma sayısı 23 firma olarak sabittir. Araştırmanın sağlıklı olması için bu durum aynı zamanda bir zorunluluktur. Gözlem kümesini oluşturan etkin firma sayıları 2014 yılında 7 firma, 2015 yılında 8 firma, 2016 y1lında 4 firma ve 2017 yılında 7 firma olmuştur. En düşük etkinlik dereceleri ise yıllar itibariyle $0.350,0.318,0.306$ ve 0.298 olarak gerçekleşmiştir. Analiz dönemi içerisinde 2015 yılında 8 firma ile en yüksek etkin firma sayısına ulaş1lırken, 2016 yılında bu sayı 4 firma ile en düşük etkin firma sayısına ulaşmıştır. Ayrıca 2017 yılı tüm yıllarda en düşük etkinlik derecesinin gerçekleştiği yıl olmuştur.

Tablo 6: Etkin Olmayan Firmaların Referans Kümeleri ve Yoğunluk Değerleri

\begin{tabular}{|c|c|c|c|c|c|c|}
\hline \multirow[t]{2}{*}{1} & \multirow[t]{2}{*}{ AKSİGORTA } & Referans Kümesi & DUBAİ STAR & EUREKO & & \\
\hline & & Yoğunluk & 0.893 & 1.130 & & \\
\hline \multirow[t]{2}{*}{2} & \multirow[t]{2}{*}{ ALLIANZ } & Referans Kümesi & EUREKO & LIBERTY & KORU & AXA \\
\hline & & Yoğunluk & 1.274 & 2.310 & 18.417 & 0.193 \\
\hline \multirow[t]{2}{*}{3} & \multirow[t]{2}{*}{ ANADOLU } & Referans Kümesi & LIBERTY & EUREKO & KORU & \\
\hline & & Yoğunluk & 1.281 & 2.188 & 6.707 & \\
\hline \multirow[t]{2}{*}{9} & \multirow[t]{2}{*}{ GENERALI } & Referans Kümesi & DUBAİ STAR & EUREKO & & \\
\hline & & Yoğunluk & 0.143 & 0.124 & & \\
\hline \multirow[t]{2}{*}{10} & \multirow[t]{2}{*}{ GROUPAMA } & Referans Kümesi & KORU & EUREKO & LIBERTY & \\
\hline & & Yoğunluk & 3.693 & 0.121 & 1.485 & \\
\hline \multirow[t]{2}{*}{11} & \multirow[t]{2}{*}{ GÜNEŞ } & Referans Kümesi & DUBAİ STAR & EUREKO & & \\
\hline & & Yoğunluk & 0.357 & 0.961 & & \\
\hline \multirow[t]{2}{*}{12} & \multirow[t]{2}{*}{ HALK } & Referans Kümesi & LIBERTY & EUREKO & KORU & \\
\hline & & Yoğunluk & 0.385 & 0.263 & 1.391 & \\
\hline \multirow[t]{2}{*}{13} & \multirow[t]{2}{*}{ HDI } & Referans Kümesi & KORU & EUREKO & LIBERTY & \\
\hline & & Yoğunluk & 1.258 & 0.350 & 1.285 & \\
\hline \multirow[t]{2}{*}{16} & \multirow[t]{2}{*}{ MAPFRE GENEL } & Referans Kümesi & KORU & EUREKO & AXA & LIBERTY \\
\hline & & Yoğunluk & 0.439 & 1.619 & 0.011 & 1.168 \\
\hline \multirow[t]{2}{*}{17} & \multirow[t]{2}{*}{ NEOVA } & Referans Kümesi & LIBERTY & EUREKO & KORU & \\
\hline & & Yoğunluk & 0.308 & 0.156 & 3.777 & \\
\hline \multirow[t]{2}{*}{18} & \multirow[t]{2}{*}{ RAY } & Referans Kümesi & DUBAİ STAR & EUREKO & & \\
\hline & & Yoğunluk & 0.548 & 0.248 & & \\
\hline \multirow[t]{2}{*}{19} & \multirow[t]{2}{*}{ SBN } & Referans Kümesi & LIBERTY & EUREKO & & \\
\hline & & Yoğunluk & 0.101 & 0.036 & & \\
\hline \multirow[t]{2}{*}{20} & \multirow[t]{2}{*}{ SOMPO JAPAN } & Referans Kümesi & LIBERTY & EUREKO & KORU & \\
\hline & & Yoğunluk & 0.282 & 0.519 & 2.287 & \\
\hline \multirow[t]{2}{*}{21} & \multirow[t]{2}{*}{ TÜRK NIIPPON } & Referans Kümesi & AXA & EUREKO & ERGO & \\
\hline & & Yoğunluk & 0.006 & 0.081 & 0.042 & \\
\hline \multirow[t]{2}{*}{22} & \multirow[t]{2}{*}{ ZİRAAT } & Referans Kümesi & LIBERTY & EUREKO & & \\
\hline & & Yoğunluk & 0.016 & 0.371 & & \\
\hline 23 & ZURİCH & Referans Kümesi & EUREKO & DUBAİ STAR & & \\
\hline & & Yoğunluk & 0.204 & 0.010 & & \\
\hline
\end{tabular}

Tablo 5.'te analizin son yılı olan 2017 yılında tam etkinlik değerini yakalayamayan firmaların etkin hale gelebilmeleri için referans almaları gereken etkin firmalar ve almaları gereken referans yoğunlukları verilmiştir. Etkin firmalar tam etkinliğe ulaşan firmalar olduğu için bu firmalar yoğunluk olarak 1.000 değerini alırlar. Tablo 5.'te etkin olmayan firmaların referans kümeleri ve yoğunluk dereceleri 
gösterildiğinden tam etkin firmalara bu tabloda yer verilmemiştir. Dolayısıyla 2017 yılında Axa, Doğa, Dubai Star, Ergo, Eureko, Koru, Liberty firmaları tam etkin olmuşlardır.

Etkin olmayan firmaların 2017 yılına göre potansiyel iyileştirme tablosuna bakıldığı zaman girdilerini etkin bir şekilde kullanamadıklarını ve girdi fazlası oluşturdukları görülmüştür. Çalışmada girdi odaklı model kullanıldığı için, Tablo 5'te etkin olmayan firmalar için bazı girdilerin belirli oranda azaltılması ile diğer firmalara kıyasla etkin ve verimli olabileceğine ilişkin iyileştirme önerileri sunulmuştur. Buna göre, ilgili firmaların çıktılarını sabit tutup, girdilerini azaltarak hedeflenen rakamlara ulaşması beklenmektedir. Bunun için, etkin olmayan firmalara referans gösterilen firmaların girdi değerleri, referans biriminin yoğunluk değeri ile çarpılarak, hedeflenen girdi değerleri hesaplanmıştır.

Tablo 7: Gözlem Kümesini Oluşturan Firmaların Malmquist Endeksi Analizi Sonuçları

\begin{tabular}{|c|c|c|c|c|}
\hline Kodu & Firmalar & 2015 Y1l Malmquist Endeksi & 2016Y11 Malmquist Endeksi & 2017 Y1l1 Malmquist Endeksi \\
\hline 1 & AKSİGORTA & 1.080 & 1.043 & 0.737 \\
\hline 2 & ALLIANZ & 1.117 & 0.886 & 1.210 \\
\hline 3 & ANADOLU & 1.014 & 0.898 & 1.006 \\
\hline 4 & AXA & 1.212 & 0.782 & 1.040 \\
\hline 5 & DOĞA & 1.607 & 0.747 & 1.308 \\
\hline 6 & DUBAİ STAR & 0.900 & 1.045 & 1.063 \\
\hline 7 & ERGO & 0.811 & 1.168 & 0.852 \\
\hline 8 & EUREKO & 0.926 & 1.094 & 1.063 \\
\hline 9 & GENERALI & 0.720 & 1.065 & 1.170 \\
\hline 10 & GROUPAMA & 0.805 & 0.955 & 0.995 \\
\hline 11 & GÜNEȘ & 0.835 & 0.855 & 0.957 \\
\hline 12 & HALK & 1.481 & 0.984 & 0.641 \\
\hline 13 & HDI & 1.005 & 1.077 & 0.937 \\
\hline 14 & KORU & 0.819 & 0.000 & 1.000 \\
\hline 15 & LIBBERTY & 0.867 & 1.220 & 1.351 \\
\hline 16 & MAPFRE GENEL & 0.955 & 0.895 & 0.965 \\
\hline 17 & NEOVA & 0.540 & 1.541 & 0.438 \\
\hline 18 & RAY & 0.971 & 0.809 & 1.104 \\
\hline 19 & SBN & 1.486 & 0.771 & 0.845 \\
\hline 20 & SOMPO JAPAN & 1.144 & 0.839 & 0.792 \\
\hline 21 & TÜRK NIPPON & 1.052 & 0.446 & 1.103 \\
\hline 22 & ZIRAAT & 1.218 & 0.907 & 1.165 \\
\hline 23 & ZURİCH & 1.015 & 0.629 & 1.136 \\
\hline
\end{tabular}

Tablo 6'da firmaların Malmquist toplam faktör verimliliği endeksine göre y1llar itibariyle gösterdikleri gelişmelere yer verilmiştir. Malmquist Üretim Endeksi dört farklı endeksin birleşiminden oluşmaktadır. Bu endeksler sırasıyla; Teknik Etkinlik Değişimi (TE), Teknolojik Değişme (TC), Saf Etkinlik Değişimi (PTE) ve Ölçek Etkinlik Değişimi (SE) Endeksleridir. Firmalar bir önceki yıla göre eğer olumlu bir gelişme gösterdiler ise endeks sonucu 1.000 rakamının üstünde bir değer, eğer olumsuz bir gelişme gösterdilerse 1.000 'den küçük bir değere sahip olacaklardır. Buna göre firmalar bazında bakacak olursak hiçbir firma analiz dönemi boyunca Malmquist Toplam Faktör Verimliliği Endeksi değerlerinde sürekli olarak bir önceki yıla göre düzenli bir artış gösterememişlerdir. Groupama, Güneş ve Mapfre Genel firmaları ise üç dönem boyunca da bir önceki yıla göre düşüş yaşamışlardır. Aksigorta'nın Malmquist Toplam Faktör Verimliliği Endeksi değerlerinde bir önceki yıla göre 2015 yılında \%8 oranında, 2016 yılında ise $\% 4.3$ artış sağlanırken 2017 yılında \%26.3'lük bir düşüş yaşanmıştır. Allianz, Anadolu, Axa, Doğa, Türk Nippon, Ziraat ve Zürich firmaları ise 2015' te bir önceki yıla göre artış gösterirlerken, 2016'da düşüş yaşamışlar ve ardından son yıl olan 2017'de tekrar Mamlquist Toplam Faktör Verimliliği değeri açısından yükselişe geçmişlerdir.

\section{SONUÇ}

Çalışmada Türkiye'de hayat dışı sigorta alanında faaliyet gösteren ve 2014-2017 yılları arasında kesintisiz veriye sahip 23 adet sigorta şirketi seçilmiştir. Uygulama kısmında ilk önce seçilen firmaların 2014, 2015, 2016 ve 2017 yıllarındaki etkinlik değerleri veri zarflama analizi yardımıyla tespit edilmiştir. Dört girdinin ve bir çıktının ele alındığı analiz, ölçeğe göre sabit getirili ve girdi odaklı oluşturulmuştur. Araştırmada kullanılan veriler T.C. Hazine ve Maliye Bakanlığ 1 tarafından yayımlanmakta olan 2014-2017 yıllarına ait Sigortacılık ve Bireysel Emeklilik Faaliyet Raporları bölümünden oluşturulmuştur. Buna göre 
etkin olan ve etkinliği yakalayamayan firmalar belirlenmiştir. Yıllar itibariyle firmaların etkinlik ortalama değerleri 2014 yılında $0.770,2015$ yılında 0.816, 2016 y1lında 0.629 ve 2017 yılında ise 0.736 olmuştur. Etkinlik değerleri açısından 2015 yılında en yüksek ortalamaya ulaşılırken, 2016 yılında düşüş görülmüş ve son yılda bir önceki yıla göre artış kaydedilmiştir. Analiz sonucu etkin olmayan firmalar için ise potansiyel iyileştirme tablosu hazırlanarak tam etkin hale gelebilmeleri için gerekli girdi seviyeleri referans verilerek gösterilmiştir. Ardından Malmquist toplam faktör verimliliğgi endeksi ile firmaların bu periyotta yıllar itibariyle gösterdikleri gelişmeler incelenmiştir. Malmquist endeks sonuçları yıllar itibariyle gösterilerek tablolaştırılmıştır. Yapılan analiz sonuçlarına göre yıllar itibariyle Malmquist toplam faktör verimliliği endeksi değerlerinde 2015 yılında 12 firmada, 2016 yılında 8 firmada, 2017 y1lında ise 13 firmada bir önceki yıla göre artış gerçekleşmiştir. Bu açıdan bakıldığında etkinlik değerleri ile Malmquist toplam faktör verimliliği değerlerinde yıllar itibariyle birbirine paralel sonuçlar ortaya çıkmıştır. 


\section{KAYNAKÇA}

Akyüz Kadri Cemil, Yıldırım İbrahim ve Balaban Yasin (2015). 'Kağıt Sektöründe Yer Alan Firmaların Veri Zarflama Analizi Yardımıyla Etkinliklerinin Ölçümü', İnternatıonal Journal of Economic and Administrative Studies, 14 : 23-38.

Altan Mitra Salimi (2010). “' Türk Sigortacılık Sektöründe Etkinlik: Veri Zarflama Analizi Yöntemi İle Bir Uygulama ‘. Gazi Üniversitesi İktisadi ve İdari Bilimler Fakültesi Dergisi, 12\1, 185-204.

Aslan Şebnem (2007). 'Performans Ölçümünde Kıyaslama Yöntemi Olarak Veri Zarflama Analizinin Kullanımı: Türkiye Şeker Fabrikaları Örneği'’. Atatürk Üniversitesi İktisadi ve İdari Biimler Dergisi, 2 (1): 383-396.

Bakırc1 Fehim ve Babacan Adem (2010). 'İktisadi ve İdari Bilimler Fakültelerinde Ekonomik Etkinlik'. Atatürk Üniversitesi İktisadi ve İdari Bilimler Dergisi, 24 (2): 215-234.

Başkaya Zehra ve Akar Cüneyt (2005). " Sigorta Şirketlerinin Satış Performanslarının Veri Zarflama Analizi Yöntemiyle Belirlenmesi'’. Muğla Üniversitesi Sosyal Bilimler Enstitüsü Dergisi, (15): 37-51.

Behdioğlu Sema ve Özcan Gözde (2009). 'Veri Zarflama Analizi ve Bankacılık Sektöründe Bir Uygulama'. Süleyman Demirel Üniversitesi İktisadi ve İdari Bilimler Fakültesi Dergisi, 14 (3): 301-326.

Bjurek Hans (1996). "'The Malmquist Total Factor Productivity Index', The Scandinavian Journal of Economics. 98 (2): 303-313.

Budak Hüseyin (2011). 'Veri Zarflama Analizi ve Türk Bankacılık Sektöründe Uygulaması'. Marmara Üniversitesi, Fen Bilimleri Dergisi, 23(3), 95-110.

Bülbül Serpil ve Akhisar İlyas (2005). "Türk Sigorta Şirketlerinin Etkinliğinin Veri Zarflama Analizi İle Araştırılması',. VII. Ulusal Ekonometri ve İstatistik Sempozyumu, 26-27.

Charnes Abraham, Cooper William Wager ve Rhodes Edwardo (1978). " Measuring the Efficiency of Decision Making Units"'. European Journal of Operations Research, (2): 429-444.

Çamlıbel Fuat, Akhisar İlyas. ve Tunay Kaşif Batu (2018). " Türk Sigorta Sektörünün Ekonomik, Politik ve Yasal Çerçevede Değerlendirilmesi'”. Journal of International Management, Educational and Economics Perspectives, 6 (1): 66-74.

Çekici Makbule Elif ve İnel Mehmet Nuri (2013). 'Türk Sigorta Sektörünün Direkt Prim Üretimlerinin Tahmin Teknikleri İle İncelenmesi’'. Marmara Üniversitesi İ.İ.B. Dergisi, 34 (1): 135-152.

Çiftçi Hakkı (2004). 'Türk Sigorta Sektörünün Sorunları: DEA Analizi İle Türk Sigorta Şirketlerinin Etkinlik Düzeylerinin Belirlenmesi'’. Çukurova Üniversitesi Sosyal Bilimler Enstitüsü Dergisi, 13, (1): 121-149.

Çolak Ömer Faruk ve Altan Şenol (2002). " Toplam Etkinlik Ölçümü: Türkiye'deki Özel ve Kamu Bankaları İçin Bir Uygulama', İktisat İşletme ve Finans, Cilt: 17, Sayı: 196, pp. 44-55.

Dalkılıç Nilüfer (2012). 'Türkiye'de Hayat Dışı Sigortacılık Sektöründe Etkinlik Analizi’’. Muhasebe ve Finansman Dergisi, 55, s. 71-90.

Deliktaş Ertuğrul (2002). " Türkiye Özel Sektör İmalat Sanayiinde Etkinlik ve Toplam Faktör Verimliliği Analizi". ODTÜ Gelişme Dergisi, METU Studies in Development, 29, (3-4), 247-284.

Diboky Franz ve Ubl Eva (2007). 'Ownership and Efficiency in the German Life İnsurance Market: A DEA Bootstrap Approach'. In 34th Seminar of the European Group of Risk and Insurance Economists (EGRIE), June, 1-40.

Dinçer Sait Erdal (2008). " Veri Zarflama Analizinde Malmquist Endeksiyle Toplam Faktör Verimliliği Değişimin İncelenmesi ve İMKB Üzerine Bir Uygulama’’. Marmara Üniversitesi İ.İ.B.F. Dergisi, 15 (2): 825-846.

Kayalı Cevdet Alptekin (2007). “' 2000-2006 Döneminde Türkiye'de Faaliyet Gösteren Sigorta Şirketlerinin Etkinlik Değerlendirmesi”’. Celal Bayar Üniversitesi İ.İ.B.F. Yönetim ve Ekonomi, 14, (2): 103-115.

Kaynar Oğuz, Zontul Metin ve Bircan Hüdaverdi (2005). " Veri Zarflama Analizi İle OECD Ülkelerinin Telekomünikasyon Sektörlerinin Etkinliğinin Ölçülmesi',. Cumhuriyet Üniversitesi İktisadi ve İdari Bilimler Dergisi, 6 (1): 37-57.

Kılıçkaplan Serdar ve Karpat Gaye (2004). ' Türkiye Hayat Sigortası Sektöründe Etkinliğin İncelenmesi' . Dokuz Eylül Üniversitesi İktisadi ve İdari Bilimler Fakültesi Dergisi, 19 (1): 1-14.

Koçak Habib ve Çilingirtürk Ahmet Mete (2011). “AB Ülkeleri ve Aday Ülkelerin Kaynak Kullanımında Etkinliklerinin Karşılaştırmalı Analizi’’. İstanbul Üniversitesi İşletme Fakültesi Dergisi, 40 (2): 166-175.

Kutlar Aziz ve Kartal Mahmut (2004). ' Cumhuriyet Üniversitelerinin Verimlilik Analizi: Fakülteler Düzeyinde Veri Zarflama Yöntemiyle Bir Uygulama’’. Kocaeli Üniversitesi Sosyal Bilimler Enstitüsü Dergisi, 8 (2): 49-79.

Lita Iulian (2018). 'Data Envelopment Analysis Technıques - DEA and Malmquist Indicators, In CRS Mode, For Measuring The Efficiency Of Romanian Public Higher Education Institutions'. Economic Computation and Economic Cybernetics Studies and Research, Issue 3/2018; Vol. 52, p. 249-264.

Luhnen Michael (2009). "Determinants of Efficiency and Productivity in German Property- Liability Insurance: Evidence for 1995-2006”. Geneva Papers on Risk \& Insurance, Vol. 34, No. 3, Jul, pp. 483-505.

Özsever Çiğdem, Gençoğlu Tülay ve Erginel Nihal (2009). ' İşgücü Verimlilik Takibi İçin Sistem Tasarımı ve Karar Destek Modelinin Geliştirilmesi'”. Dumlupınar Üniversitesi Fen Bilimleri Dergisi, 18: 45-58.

Sarı Zuhal (2015). "Veri Zarflama Analizi ve Bir Uygulama'. Yüksek Lisans Tezi, Hacettepe Üniversitesi Fen Bilimleri Enstitüsü, İstatistik Anabilim Dalı, Ankara.

Şahin İbrahim Erem. Şirket Birleşmelerinin Etkinlik Açısından Değerlendirilmesi ve Türk Bankacılık Sektöründe Bir Uygulama, Konya, Aybil Yayınları, 2012. 
Şahin İsmet (2008). “' Sağlık Bakanlığı Genel Hastaneleri ve Sağlık Bakanlığına Devredilen SSK Genel Hastanelerinin Teknik Verimliliklerinin Karşılaştırmalı Analizi’. Hacettepe Sağlık İdaresi Dergisi, 11 (1): 1-48.

Tetik Semra (2003). "' İşletme Performansını Belirlemede Veri Zarflama Analizi', Celal Bayar Üniversitesi İ.İ.B.F. Yönetim ve Ekonomi, 10 (2): 221-229.

Ulucan Aydın (2000). 'Şirket Performanslarının Ölçülmesinde Veri Zarflama Analizi Yaklaşımı: Genel ve Sektörel Bazda Değerlendirmeler'. Hacettepe Üniversitesi İktisadi ve İdari Bilimler Fakültesi Dergisi, 18 (1): $405-418$.

Yeşilyurt Cavit (2009). " Türkiye'deki İktisat Bölümlerinin Göreceli Performanslarının Veri Zarflama Analizi Yöntemiyle Ölçülmesi: KPSS 2007 Verilerine Dayalı Bir Uygulama'’. Atatürk Üniversitesi İktisadi ve İdari Bilimler Dergisi, 23 (4): 135-147. 